\title{
Tide Height Calculation by Using the Nesting Surge Model
}

\author{
Md. Towhiduzzaman
}

\begin{abstract}
In this study, a doubly nested tide-surge model was established for the coastal region of Bangladesh. This model can be applied in coastal Belt Tide Height Calculation. A uniform grid model is being converted to the region between $21^{\circ} \mathrm{N}$ to $23^{\circ} \mathrm{N}$ and $89^{\circ} \mathrm{E}$ to $90^{\circ} \mathrm{E}$ in a $\frac{1}{120^{\circ}}$ grid resolution. The model equations were solved by semi-implicit finite difference technique. An appropriate tidal condition over the model domain could be generated in the sea level to be oscillatory. To the northeast corner, the Meghna River in Bangladesh discharge and rainfall distribution was taken into account. The results of Nesting Surge model are found to be a reasonable agreement with those observed data from Bangladesh inland water transport authority (BIWTA). So, the Tide Height Calculation is a significant matter here to be discussed.
\end{abstract}

Index Terms - Coast, continuity equation, cyclone, fluids, storm surge, tide, tide generating force.

\section{INTRODUCTION}

The coastal region of Bangladesh is full of many small and big islands and the coast is very irregular in shape. Among all the natural catastrophes, tropical storms relating the tidal surges are the most devastating in nature along the coast of Bangladesh. The inundation that results due to the surges has caused a loss of countless lives and assets of the country. Even though, the strong wind plays the principal role for developing surge levels in the time of a storm, several factors namely, astronomical tide, off-shore islands, river, discharge, shallow bathymetry, bending of coastline can contribute to lift up the levels. Consequently, it is indispensable to have a sound knowledge of the facts that affect surge along the coastal region of Bangladesh to enable their accurate prediction. Moreover, the head of the Bay of Bengal is a large tidal range area. Thus, if a storm approaches the coast during high tide, water level due to tide-surge becomes significantly high. The experimentation and calculation on storm surge, the tide and their interactions can be trialed by many authors for the Bay of Bengal region. But investigations including offshore islands are limited. The storm surge model used in this work has been developed by the Indian Institute of Technology (IIT). Besides, the same model is used for the functional storm surge forecasting in the region a task for which it has shown accuracy. The IIT model is a fully nonlinear, depthaveraged, hydrodynamic storm surge model, forced by the cyclone wind field model. Therefore, the predicted water levels at the coast from the IIT model were used as the

Published on January 23, 2017

Md. Towhiduzzaman is a Lecturer in Mathematics, Department of Electrical \& Electronic Engineering, Uttara University (UU), Dhaka-1230, Bangladesh.(e-mail: towhid.math.iu@gmail.com) coastal boundary condition to force the model of the flooding inland.

In the present study, the model is improved by nesting a very fine grid model into the fine grid model as well as extending the fine grid model for the whole coastal belt instead of Meghna estuarine region, where the very fine grid model is designed to incorporate river discharge, all offshore islands irrespective of small and big between Barisal and Chittagong in Bangladesh as well as coastal bending very accurately. The model is incorporating the tide height also [1]-[5].

\section{MATERIALS AND METHOD}

\section{A. Study Area}

Bangladesh is a deltaic land of about 147,570 square km area having great Himalayas to the north and the vast Bay of Bengal on the south. It is a south Asian country extending from Latitude $20^{\circ} 45^{\prime} \mathrm{N}$ to $26^{\circ} 40^{\prime} \mathrm{N}$ and from Longitude $88^{\circ} 05^{\prime} \mathrm{E}$ to $92^{\circ} 40^{\prime} \mathrm{E}$. Bangladesh has about $24,000 \mathrm{~km}$ of rivers, streams and canals that together cover about $7 \%$ of the country's surface. The river system of Bangladesh is highly complex and dominated by three major rivers namely the Ganga (Padma), the Brahmaputra and the Meghna which formed the world's largest delta. It has a complex coastline of about $710 \mathrm{~km}$ and long continental shelf with shallow bathymetry. The Bay of Bengal creates a funneling form to the Meghna estuary in the storm surge which is the maximum extent here in this world nowadays. Tropical storms along with associated tidal surges often cause great devastation along the coast of Bangladesh with Meghna estuarine region being specifically vulnerable. According to Smith, storms and tides kill globally, on average, 15,000 people annually. The Bay of Bengal is the region over where about $5 \%$ of the global tropical cyclones form. In 1970, one of the most devastating cyclones of the century struck Meghna estuary of Bangladesh killing about 300,000 people. 1991 April Cyclone made landfall near Chittagong which killed about 1, 38,000 people. In both the cases, the landfall was started in the time of high astronomical tides, as a result the loss of lives was colossal. The cyclone Aila furiously hit south-western coast of Bangladesh in May, 2009 which killed 147 and tidal waves leaping up to 13 feet To simulate storm surge in the coast of Bangladesh numerical scheme is considered. The coarse mesh scheme (CMS) covers the area between $15^{\circ} \mathrm{N}$ to $23^{\circ} \mathrm{N}$ latitude and $85^{\circ} \mathrm{E}$ to $95^{\circ} \mathrm{E}$ longitudes. A Nested into a coarse mesh scheme (CMS) is said to be the high resolution numerical scheme (FMS). Again, a very fine mesh scheme (VFMS) is nested in the FMS. The FMS covers the area between $21.15^{\circ}$ $\mathrm{N}$ to $23^{\circ} \mathrm{N}$ latitudes and $89^{\circ} \mathrm{E}$ to $92^{\circ} \mathrm{E}$ longitudes. The 
VFMS covers the area between $21.77^{\circ} \mathrm{N}$ to $23^{\circ} \mathrm{N}$ latitudes and $90.40^{\circ} \mathrm{E}$ to $92^{\circ} \mathrm{E}$ longitudes. The present study develops a numerical model of storm surges along the coast of Bangladesh extending from latitudes $15^{\circ} \mathrm{N}$ to $23^{\circ} \mathrm{N}$ and from longitudes $85^{\circ} \mathrm{E}$ to $95^{\circ} \mathrm{E}$ and incorporating at most offshore islands and evaluate the inundation area due to the surge [6]-[10].

\section{B. Basic Equations}

In the formulation of the model, a system of rectangular Cartesian coordinates is considered where the curvature of the surface of the earth is assumed to be zero with a horizontal xy-plane and $\mathrm{z}$-axis in the upward direction. If the horizontal length scale is bigger than the vertical one, then the $\mathrm{z}$ component of the momentum equation may be approximated by the hydrostatic equation. If the density variation is negligible, the continuity equation reduces to the non divergence of velocity. With these approximations and neglecting the molecular viscosity, the basic shallow water equations are obtained [11]:

$$
\begin{aligned}
& \frac{\partial u}{\partial x}+\frac{\partial v}{\partial y}+\frac{\partial w}{\partial z}=0 \\
& \frac{\partial u}{\partial t}+u \frac{\partial u}{\partial x}+v \frac{\partial u}{\partial y}+w \frac{\partial u}{\partial z}-f v=-\frac{1}{\rho} \frac{\partial p}{\partial x}-F_{x} \\
& \frac{\partial v}{\partial t}+u \frac{\partial v}{\partial x}+v \frac{\partial v}{\partial y}+w \frac{\partial v}{\partial z}+f u=-\frac{1}{\rho} \frac{\partial p}{\partial y}-F_{y} \\
& \frac{\partial p}{\partial z}=-\rho g
\end{aligned}
$$

where $u, v, w$ are the instantaneous velocity components; $\mathrm{P}$ the pressure; $\rho$ the density of the sea water supposed to be homogeneous;

$f=2 \Omega \sin \varphi$ the Coriolis parameter, where $\Omega$ is the angular speed of the earth rotation and $\varphi$ is the latitude of the place of interest and $g$ the acceleration due to gravity.

Now, using equations (1), (2) and (3), the vertically integrated shallow water equations in flux form can be given by [12]-[14]:

$$
\begin{aligned}
& \frac{\partial \zeta}{\partial t}+\frac{\partial \tilde{u}}{\partial x}+\frac{\partial \tilde{v}}{\partial y}=0 \\
& \frac{\partial \tilde{u}}{\partial t}+\frac{\partial}{\partial x}(u \tilde{u})+\frac{\partial}{\partial y}(v \tilde{u})=f \tilde{v}-g(\zeta+h) \frac{\partial \zeta}{\partial x}+\frac{T_{x}}{\rho}- \\
& \frac{\rho C_{f}}{\zeta+h} \tilde{u}\left(u^{2}+v^{2}\right)^{\frac{1}{2}}+g \frac{\partial T}{\partial x}(\zeta+h)
\end{aligned}
$$

and

$$
\begin{aligned}
& \frac{\partial \tilde{v}}{\partial t}+\frac{\partial}{\partial x}(u \tilde{v})+\frac{\partial}{\partial y}(v \tilde{v})=-f \tilde{u}-g(\zeta+h) \frac{\partial \zeta}{\partial y}+\frac{T_{y}}{\rho}- \\
& \frac{\rho C_{f}}{\zeta+h} \tilde{v}\left(u^{2}+v^{2}\right)^{\frac{1}{2}}+g \frac{\partial T}{\partial y}(\zeta+h)
\end{aligned}
$$

$$
\text { Where } u(\zeta+h)=\tilde{u} \text { and } v(\zeta+h)=\tilde{v}
$$

\section{Boundary Conditions}

The normal component of the depth regular speed at the closed frontier, coastal belts of the main land and island is set to zero and for open boundaries, radiation nature of boundary states are applied to allow the troubles, normalizations within the model zones and to set outs through the open boundaries. The western and eastern open sea areas are positioned in parallel to $\mathrm{x}$-axis as well as the southern open sea boundary positioned in parallel to $y$-axis.
The radiation limit condition for the western, eastern and southern open sea boundaries due to be [15]-[17]:

$$
\begin{aligned}
& v+\left(\frac{g}{h}\right)^{\frac{1}{2}} \zeta=0 \\
& v-\left(\frac{g}{h}\right)^{\frac{1}{2}} \zeta=0 \\
& u-\left(\frac{g}{h}\right)^{\frac{1}{2}} \zeta=-\left(\frac{g}{h}\right)^{\frac{1}{2}} a \sin \left(\frac{2 \pi t}{T}+\varphi\right)
\end{aligned}
$$

where $a, \varphi$ and $T$ are the amplitude, phase and period respectively of the tidal constituent.

\section{Setup of Nested Models}

In order to incorporate all offshore islands along the coastal region of Bangladesh very accurately in a numerical model, a very fine resolution is needed but it may involve numerical instability with more computing time. On the other hand, the analysis area should considerably be big so that a storm can move over it for 2-3 days before crossing the coast. Considering the facts, the study uses nested models. The features of these models are that they allow specification of extreme resolution in a longing province of interest only with minor resolution elsewhere. In this study, a high-resolution fine grid model (FGM), capable of incorporating all major islands, is Nested into a coarse grid model (CGM). To take into account the thickly populated low lying small and big islands between Barisal and Chittagong in Bangladesh and extreme bending of the coast line very accurately, a very fine grid model (VFGM) is again nested into the FGM [18]-[21].

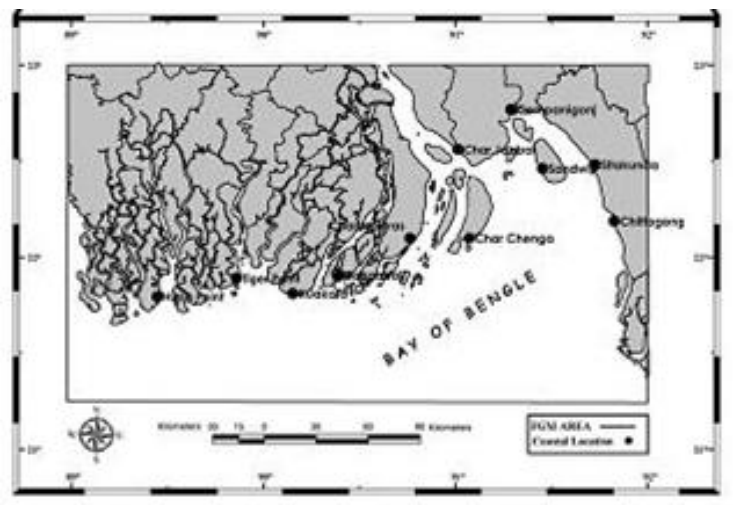

Fig. 1. Domains of different models along with positions of some coastal locations at which water levels are presented.

\section{E. Grid Generation}

In the numerical solution, the area under consideration is covered by a two dimensional mesh of rectangular grids. The governing equations are given by the equations (5) \& (7) as well as the boundary conditions is given by the equations (8), (9), (10) are described by finite difference method using a staggered grid system to solve the shallow water equations by conditionally stable semi implicit method. If $(i, j)$ denote the discrete grid points in the xyplane, $\zeta$ is computed at each grid point where $i$ is even and $j$ is odd, $v$ is computed at each grid point where both $i$ and $j$ is even, $u$ is computed at each grid point where both $i$ and $j$ is odd. These are known as the staggered grid system.

The details of the staggered grid system are shown in Fig. 2. 


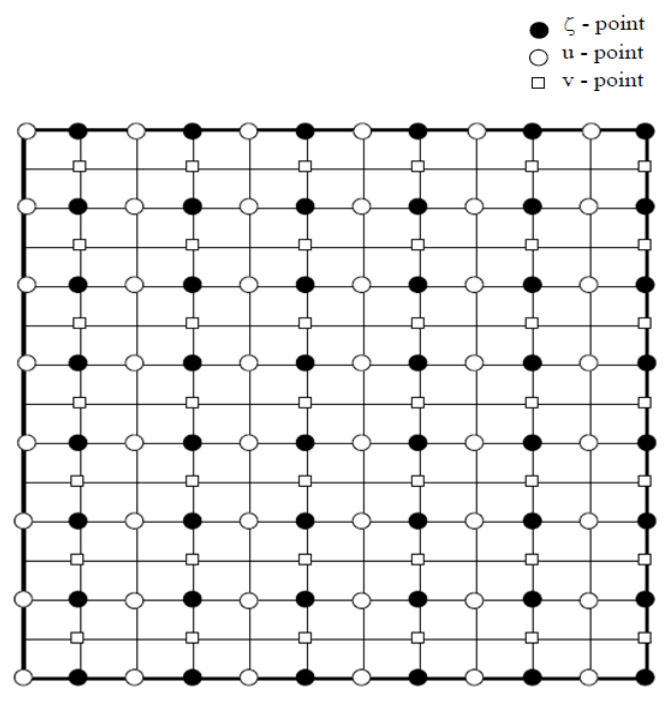

Fig. 2. The used staggered grid system.

\section{F. Discretizations of Governing Equation}

The governing equations as well as the boundary conditions developed in previously are summarized and the discretizations of the equations by finite difference (forward in time and central in space) method. The purpose of space discretization the following notations are used for conciseness and clarity.

With these transformations, equation (5) now can be transformed to the following discrete equation

$$
\zeta_{i, j}^{k+1}=\zeta_{i, j}^{k}-\Delta t[T L 1+T L 2]
$$

where

$$
T L 1=\frac{\widetilde{u}_{i+1, j}^{k}-\tilde{u}_{i-1, j}^{k}}{2 \Delta x}
$$

and

$$
T L 2=\frac{\tilde{v}_{i, j+1}^{k}-\tilde{v}_{i, j-1}^{k}}{2 \Delta y}
$$

$\zeta_{i, j}^{k+1}$ in equation (11) is computed at $\mathrm{i}=2,4,6, \ldots \ldots$ $\ldots, \quad \mathrm{M}-2$ and $\mathrm{j}=3,5,7, \ldots \quad \ldots \quad \ldots, \mathrm{N}-2$.

Now, for each term of equation (6) the following transformations are taken into account

$$
\begin{aligned}
& \frac{\partial \tilde{u}}{\partial t}=\frac{\tilde{u}_{i, j}^{k+1}-\tilde{u}_{i, j}^{k}}{\Delta t} \\
& \frac{\partial}{\partial x}(u \tilde{u})=\frac{u_{i+2, j}^{k} \tilde{u}_{i+2, j}^{k}-u_{i-2, j}^{k} \tilde{u}_{i-2, j}^{k}}{4 \Delta x} \\
& \frac{\partial}{\partial y}(v \tilde{u})=\frac{\overline{v_{i, j+1}^{k}} x \overline{\tilde{u}_{i, j+1}^{k}}-\overline{v_{i, j-1}^{k}} x \overline{\tilde{u}_{i, j-1}^{k}} y}{2 \Delta y} \\
& f v=-f_{i}{\overline{\tilde{v}_{i, j}^{k}}}^{x y} \\
& g(\zeta+h) \frac{\partial \zeta}{\partial x}=-g\left(\zeta_{i, j}^{k+1}+h_{i, j}\right) \frac{\zeta_{i+1, j}^{k+1}-\zeta_{i-1, j}^{k+1}}{2 \Delta x} \\
& \frac{T_{x}}{\rho}=\frac{\tau_{x}}{\rho} \\
& g(\zeta+h) \frac{\partial \tau}{\partial x}=-g\left(\zeta_{i, j}^{k+1}+h_{i, j}\right) \frac{\tau_{i+1, j}^{k+1}-\tau_{i-1, j}^{k+1}}{2 \Delta x}
\end{aligned}
$$

$$
\frac{C_{f}}{\zeta+h}\left(u^{2}+v^{2}\right)^{\frac{1}{2}}=\frac{C_{f} \sqrt{u_{i, j}^{k^{2}}+\left({\overline{v_{i, j}^{k}}}^{x y}\right)}}{\zeta_{i, j}^{k+1}+h_{i, j}}
$$

Then equation (6) converted to the form

$$
\frac{\widetilde{u}_{i, j}^{k+1}-\widetilde{u}_{i, j}^{k}}{\Delta t}=-T L 1-T L 2-T L 3+T R 1+T R 2+T R 3-
$$

Where

$$
\begin{aligned}
& T L 1=\frac{u_{i+2, j}^{k} \widetilde{u}_{i+2, j}^{k}-u_{i-2, j}^{k} \widetilde{u}_{i-2, j}^{k}}{4 \Delta x}
\end{aligned}
$$

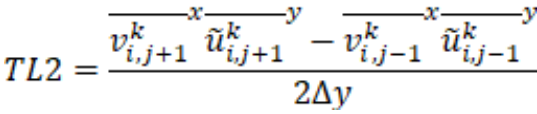

$$
\begin{aligned}
& T L 3=-f_{i}{\overline{v_{i, j}^{k}}}^{x y} \\
& T R 1=-g\left(\zeta_{i, j}^{k+1}+h_{i, j}\right) \frac{\zeta_{i+1, j}^{k+1}-\zeta_{i-1, j}^{k+1}}{2 \Delta x} \\
& T R 2=\frac{\tau_{x}}{\rho} \\
& T R 3=-g\left(\zeta_{i, j}^{k+1}+h_{i, j}\right) \frac{\tau_{i+1, j}^{k+1}-\tau_{i-1, j}^{k+1}}{2 \Delta x} \\
& \text { FR1 }=\frac{C_{f} \sqrt{u_{i, j}^{k^{2}}+\left({\overline{v_{i, j}^{k}}}^{x y}\right)}}{\zeta_{i, j}^{k+1}+h_{i, j}}
\end{aligned}
$$

Equation (12) can be simplified in the following way:

$\tilde{u}_{i, j}^{k+1}-\tilde{u}_{i, j}^{k}=\Delta t\left(-T L 1-T L 2-T L 3+T R 1+T R 2+T R 3-\tilde{u}_{i, j}^{k+1} F R 1\right)$ or, $\tilde{u}_{i, j}^{k+1}=\tilde{u}_{i, j}^{k}+\Delta t\left(-T L 1-\mathrm{TL} 2-\mathrm{TL} 3+\mathrm{TR} 1+\mathrm{TR} 2+\mathrm{TR} 3-\tilde{\mathrm{u}}_{\mathrm{i}, \mathrm{j}}^{\mathrm{k}+1} \mathrm{FR} 1\right)$ or, $\tilde{u}_{i, j}^{k+1}=\tilde{u}_{i, j}^{k}-\Delta t(T L 1+T L 2+T L 3)+\Delta t(T R 1+T R 2+T R 3)-\Delta t\left(\tilde{u}_{i, j}^{k+1} F R 1\right)$ or, $\tilde{u}_{i, j}^{k+1}+\Delta t\left(\tilde{u}_{i, j}^{k+1} F R 1\right)=\tilde{u}_{i, j}^{k}-\Delta t(T L 1+T L 2+T L 3)+\Delta t(T R 1+T R 2+T R 3)$

or, $\tilde{u}_{i, j}^{k+1}=\frac{\tilde{u}_{i, j}^{k}-\Delta \mathrm{t}(\mathrm{TL} 1+\mathrm{TL} 2+\mathrm{TL} 3)+\Delta \mathrm{t}(\mathrm{TR} 1+\mathrm{TR} 2+\mathrm{TR} 3)}{(1+\Delta \mathrm{tFR} 1)}$

$\tilde{u}_{i, j}^{k+1}$ in equation (13) is computed at $\mathrm{i}=3,5,7, \ldots \ldots \ldots$, $\mathrm{M}-1$ and $\mathrm{j}=3,5,7, \ldots \ldots \ldots, \mathrm{N}-2$.

Again, for converting equation (7) from continuous operator problem to discrete one, the following transformations are used:

$$
\begin{aligned}
& \frac{\partial \tilde{v}}{\partial t}=\frac{\tilde{v}_{i, j}^{k+1}-\tilde{v}_{i, j}^{k}}{\Delta t} \\
& \frac{\partial}{\partial x}(u \tilde{v})=\frac{\frac{\Delta t}{u_{i+1, j}^{k}} y \frac{\hat{v}_{i+1, j}^{k}}{x}-\overline{u_{i-1, j}^{k}} y \frac{v_{i-1, j}^{k}}{\tilde{v}_{i, j}}}{2 \Delta x} \\
& \frac{\partial}{\partial y}(v \tilde{v})=\frac{v_{i, j+2}^{k} \widetilde{v}_{i, j+2}^{\mathrm{k}}-\mathrm{v}_{\mathrm{i}, \mathrm{j}-2}^{\mathrm{k}} \widetilde{\mathrm{v}}_{\mathrm{i}, \mathrm{j}-2}^{\mathrm{k}}}{4 \Delta \mathrm{y}} \\
& \mathrm{fu}=-\mathrm{f}_{\mathrm{i}} \overline{\mathrm{u}}_{\mathrm{i}, \mathrm{i}}^{\mathrm{ky}} \\
& g(\zeta+h) \frac{\partial \zeta}{\partial x}=-g\left(\zeta_{i, j}^{k+1}+\mathrm{h}_{\mathrm{i}, \mathrm{j}}\right) \frac{\zeta_{\mathrm{i}, \mathrm{j}+1}^{\mathrm{k}+1}-\zeta_{\mathrm{i}, \mathrm{j}-1}^{\mathrm{k}+1}}{2 \Delta \mathrm{y}} \\
& \frac{T_{y}}{\rho}=\frac{\tau_{y}}{\rho} \\
& g(\zeta+h) \frac{\partial \tau}{\partial y}=-g\left(\zeta_{i, j}^{k+1}+h_{i, j}\right) \frac{\tau_{i, j+1}^{k+1}-\tau_{i, j-1}^{k+1}}{2 \Delta y}
\end{aligned}
$$

and

$$
\frac{C_{f}}{\zeta+h}\left(u^{2}+v^{2}\right)^{\frac{1}{2}}=\frac{C_{f} \sqrt{\left({u_{i, j}^{k}}^{\mathrm{xy}}\right)^{2}+\mathrm{v}_{\mathrm{i}, \mathrm{j}}^{\mathrm{k}^{2}}}}{\zeta_{\mathrm{i}, \mathrm{j}}^{\mathrm{k}+1}+\mathrm{h}_{\mathrm{i}, \mathrm{j}}}
$$


Using these values in (7),

$$
\begin{aligned}
& \frac{\tilde{v}_{i, j}^{k+1}-\tilde{v}_{i, j}^{k}}{\Delta t}=-\mathrm{TL} 1-\mathrm{TL} 2-\mathrm{TL} 3+\mathrm{TR} 1+\mathrm{TR} 2+\mathrm{TR} 3- \\
& \widetilde{\mathrm{V}}_{\mathrm{i}, j}^{\mathrm{k}+1} \mathrm{FR} 1
\end{aligned}
$$

where

$$
\begin{aligned}
& T L 1=\frac{{\overline{u_{i+1, j}^{k}}}^{y} \overline{\tilde{v}_{i+1, j}^{k}} x-\overline{u_{i-1, j}^{k}} y \overline{\tilde{v}_{i-1, j}^{k}} x}{2 \Delta x} \\
& T L 2=\frac{v_{i, j+2}^{k} \widetilde{v}_{i, j+2}^{k}-v_{i, j-2}^{k} \widetilde{v}_{i, j-2}^{k}}{4 \Delta y} \\
& T L 3=f_{i}{\overline{u_{i, j}^{k}}}^{x y} \\
& T R 1=-g\left(\zeta_{i, j}^{k+1}+h_{i, j}\right) \frac{\zeta_{i, j+1}^{k+1}-\zeta_{i, j-1}^{k+1}}{2 \Delta y} \\
& T R 2=\frac{\tau_{y}}{\rho} \\
& T R 3=-g\left(\zeta_{i, j}^{k+1}+h_{i, j}\right) \frac{\tau_{i, j+1}^{k+1}-\tau_{i, j-1}^{k+1}}{2 \Delta y} \\
& F R 1=\frac{C_{f} \sqrt{\left({u_{i, j}^{k}}^{x y}\right)^{2}+v_{i, j}^{k^{2}}}}{\zeta_{i, j}^{k+1}+h_{i, j}}
\end{aligned}
$$

Equation (14) can be simplified in the following way:

$\tilde{v}_{i, j}^{k+1}-\tilde{v}_{i, j}^{k}=\Delta t\left(-T L 1-T L 2-T L 3+T R 1+T R 2+T R 3-\tilde{v}_{i, j}^{k+1} F R 1\right)$ or,$\tilde{v}_{i, j}^{k+1}=\tilde{v}_{i, j}^{k}+\Delta t\left(-T L 1-T L 2-T L 3+T R 1+T R 2+T R 3-\tilde{v}_{i, j}^{k+1} F R 1\right)$ or, $\tilde{v}_{i, j}^{k+1}=\tilde{v}_{i, j}^{k}-\Delta t(T L 1+T L 2+T L 3)+\Delta t(T R 1+T R 2+T R 3)-\Delta t\left(\tilde{v}_{i, j}^{k+1} F R 1\right)$ or,$\hat{v}_{i, j}^{k+1}+\Delta t\left(\hat{v}_{i, j}^{k+1} F R 1\right)=\hat{v}_{1, j}^{k}-\Delta t(T L 1+T L 2+T L 3)+\Delta t(T R 1+T R 2+$ TR3) or, $\tilde{v}_{i, j}^{k+1}=\frac{\tilde{v}_{i, j}^{k}-\Delta t(T L 1+T L 2+T L 3)+\Delta t(T R 1+T R 2+T R 3)}{(1+\Delta t . F R 1)}$

$\tilde{v}_{i, j}^{k+1}$ in equation (15) is computed at $\mathrm{i}=2,4,6, \ldots \ldots \ldots$, $\mathrm{M}-2$ and $\mathrm{j}=2,4,6, \ldots \ldots \ldots, \mathrm{N}-1$.

The western boundary condition $v+\left(\frac{g}{h}\right)^{\frac{1}{2}} \zeta=0$ can be written as:

$$
\zeta=-\sqrt{\left(\frac{h}{g}\right) v}
$$

Discretization of the condition:

$$
\frac{\zeta_{i, 1}^{k+1}+\zeta_{i, 3}^{k+1}}{2}=-\sqrt{\left(\frac{h_{i, 2}}{g}\right)} v_{i, 2}^{k}
$$

where the values of average $\zeta$ is taken on the left hand side. After rearranging the terms, the final form is obtained:

$$
\zeta_{i, 1}^{k+1}=-\zeta_{i, 3}^{k+1}-2 \sqrt{\left(\frac{h_{i, 2}}{g}\right)} v_{i, 2}^{k}
$$

where $\mathrm{i}=2,4,6$, M-2.

Here $\zeta$ will always be calculated at advanced stages.

Similarly for eastern and southern boundaries respectively,

$$
\zeta_{i, n}^{k+1}=-\zeta_{i, n-2}^{k+1}-2 \sqrt{\left(\frac{h_{i, n-1}}{g}\right)} v_{i, n-1}^{k}
$$

where $\mathrm{i}=2,4,6, \ldots \ldots \ldots, \mathrm{M}-2$.

$$
\zeta_{m, j}^{k+1}=-\zeta_{m-2, j}^{k+1}+2 \sqrt{\left(\frac{h_{m-1, j}}{g}\right)} u_{m-1, j}^{k}+4 a \sin \left(\frac{2 \pi t}{T}+\varphi\right)(18)
$$

where $\mathrm{i}=1,3,5, \ldots \ldots \ldots, \mathrm{N}$.

\section{RESULTS AND DISCUSSION}

It may be found that at Hiron point the surge height associated with tide and without tide are displayed. The difference of these two data is representing the tide height The Surge height of 1991 at Hiron point without tide is shown in Fig. 3.

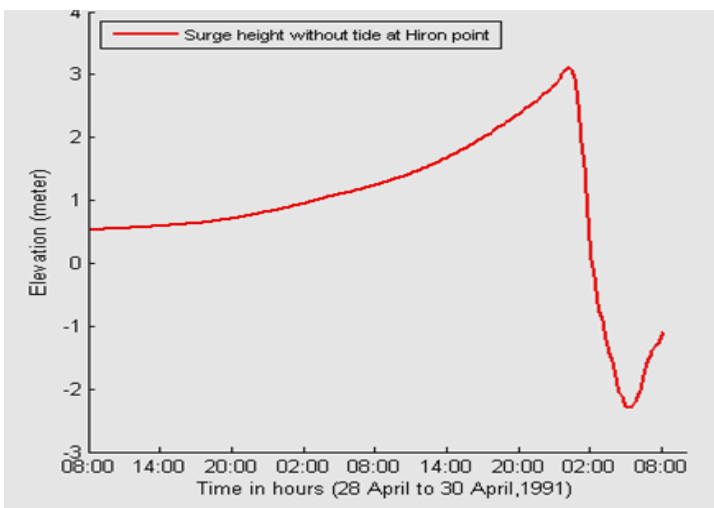

Fig. 3. Surge height of 1991 at Hiron point without tide.

The Surge height of 1991 at Hiron point with tide is shown in Fig. 4.

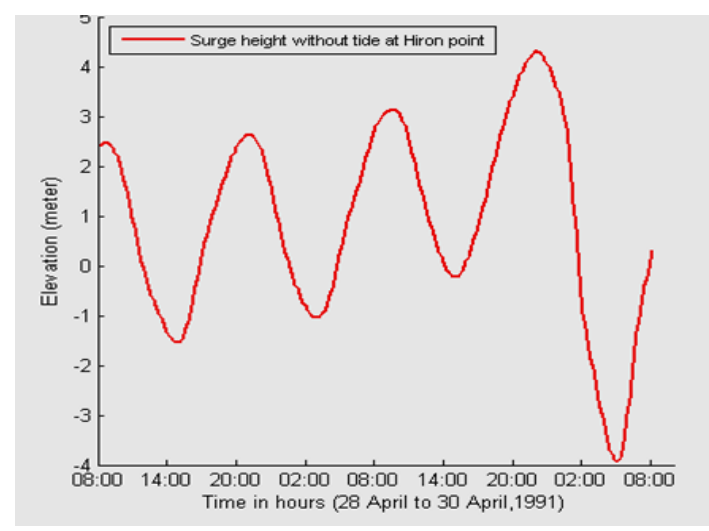

Fig. 4. Surge height of 1991 at Hiron point with tide.

Finally, it may be found the comparison between the surge model tide data and the Bangladesh inland water transport authority (BIWTA) tide data shown in Fig. 5.

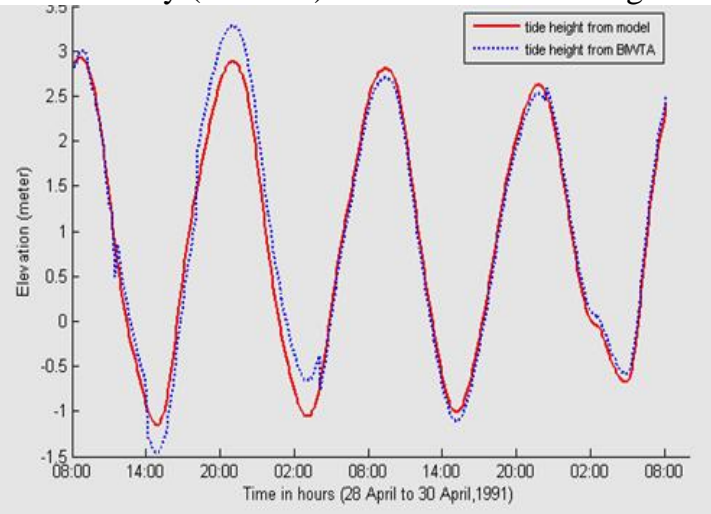

Fig. 5. Comparison between the tide from the surge model data and the BIWTA tide data. 


\section{CONCLUSION}

In this study, doubly nested numerical model was used, the IIT model simulation results were found to be reasonable. The water levels were found to be influenced by both offshore islands and river discharge. Thus, in order to calculate tide height very accurately along the region, the above calculation is followed. Thus, a uniform can be converted to a particular grid resolution. The model equations were resolved in different techniques. It can also be the model in the sea level to be oscillatory. The results of IIT model are to be a sensible harmony with those scrutinized data from Bangladesh inland water transport authority (BIWTA). So, the Tide Height Calculation regarding the above facts is a significant matter here to be discussed. If it is measured well by this hypothesis I have given here so far, the natural disasters might be controlled in a great extent and the world can have a new dimension to protect the whole humanity from extreme coastal disasters. Scientifically, this method can be really an epoch-making way in the contemporary ages by having a profound knowledge over this. It can also be a great subject matter for the future researches at home and abroad.

\section{REFERENCES}

[1] Gour Chandra Paul, Ahmad Izani Md. Ismail, "Contribution of offshore islands in the prediction of water levels due to tide-surge interaction for the coastal region of Bangladesh", Natural Hazards, vol.65, no.1, pp 13-25, January 2013.

[2] Md. Towhiduzzaman, "Performance Analysis of Continuity Equation and Its Applications", European Journal of Engineering Research and Science (EJERS), vol. 1, no. 5, pp. 40-43, 2016.

[3] As-Salek JA, "Negative surges in the Meghna estuary in Bangladesh", Mon Weather Rev., vol. 125, pp. 1638-1648, 1997.

[4] Dube SK, Chittibabu P, Sinha PC, Rao AD, "Numerical modelling of storm surge in the head Bay of Bengal using location specific model", Natural Hazards, vol. 31, pp. 437-453, 2004.

[5] Jain SK, Agarwal PK, Singh VP, "Hydrology and water resources of India", Springer, Dordrecht, pp. 308, 2007.

[6] Roy GD, "Sensitivity of water level associated with tropical storms along the Meghna estuary in Bangladesh", Environ Int., vol. 25, no. 1, pp. 109-116, 1999 .

[7] T. S. Murty, R. A. Flather, R. F., Henry, "The storm surge problem in the Bay of Bengal", Progress Oceanograph., vol. 16, pp. 195-233, 1986.

[8] R. A. Flather, "A tidal model of the northeast Pacific", Atmosphere Ocean, vol. 25, pp. 22-45, 1987.

[9] S. K. Dube, I. Jain, A. D. Rao, T. S. Murty, "Storm surge modeling for the Bay of Bengal and Arabian Sea", Natural Hazards, vol. 51, pp. 3-27, 2009.
[10] M. M. Rahaman, G. C. Paul, A. Haque, "Nested numerical scheme in a polar coordinate shallow water model for the coast of Bangladesh", J. Coast Conserv., vol. 17, no. 1, pp. 37-47, 2013.

[11] Gour Chandra Paul, Ahmad Izani Md Ismail, "Numerical modeling of storm surges with air bubble effects along the coast of Bangladesh", Ocean Engineering, vol. 42, pp. 188-194, March 2012.

[12] Jeffrey D. Kepert, "The dynamics of boundary layer jets within the tropical cyclone core. Part I: Linear theory", Journal of Atmospheric Science, vol. 58, no. 17, pp. 2469-2484, 2001.

[13] J. L. Franklin, M. L. Black, and K. Valde, "GPS dropwindsonde wind profiles in hurricanes and their operational implications", Weather and Forecasting, vol. 18, no. 1, pp. 32-44, 2003.

[14] S. K. Debsarma, "Simulation of storm surges in the Bay of Bengal", Mar Geod., 32, pp. 178-198, 2009.

[15] Jain, I., Rao, A. D., Jitendra, V. and Dube, S. K., "Computation of expected total water levels along the east coast of India", Journal of Coastal Research, vol. 26, no. 4, pp. $681-687,2010$.

[16] Karim, M. F. and Mimura, N., "Impacts of climate change and sealevel rise on cyclonic storm surge floods in Bangladesh", Global Environmental Change, vol. 18, no. 3, pp. 490-500, 2008.

[17] Neetu Agnihotri, Chittibabu, P., Indu Jain, Rao, A. D., Dube, S. K., Sinha P. C., "A Bay-River Coupled Model for storm surge prediction along the Andhra coast of India", Natural Hazards, vol. 39, no. 1, pp. 83-101, 2006.

[18] Md. Towhiduzzaman, "Prediction of Tide Height Using the Discrete Fourier Transform", American Journal of Engineering Research (AJER), vol. 5, no. 12, pp. 87-94, 2016.

[19] M. Mizanur Rahman, G. Chandra Paul and A. Hoque, "A Cyclone Induced Storm Surge forecasting Model for the coast of Bangladesh with Application to the Cyclone Sidr", International Journal of Mathematical Modelling and Computations, vol. 1, no. 2, pp. 77-86, 2011.

[20] Hussain Farzana, “A Transformed Coordinates Shallow water Model for the Head of the Bay of Bengal using Boundary-Fitted Curvilinear Grids", East Asian Journal on Applied Mathematics, vol. 3, no. 1, pp. 27-47, 2013.

[21] Dube, S. K., Indu Jain, Rao, A. D., T. S. Murty, "Storm surge modeling for the Bay of Bengal and Arabian Sea", Natural Hazards, vol. 51, no. 1, pp. 3-27, 2009.

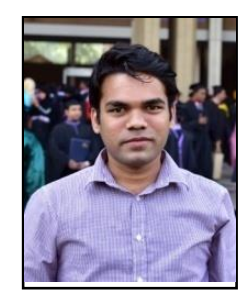

Md. Towhiduzzaman was born in $1^{\text {st }}$ November, 1986. His birth place is at Kushtia in Bangladesh He received the B.Sc. (2010) and M.Sc. (2011) degree from Islamic University, Kushtia, Bangladesh in Applied Mathematics. Presently, he has been living at Uttara, Dhaka, Bangladesh for the last 3 years. He has been working as a Lecturer in Mathematics, Department of Electrical \& Electronic Engineering, Uttara University (UU), Dhaka, Bangladesh for 3 years.

His research interests are in the Operation Research, Fluid Dynamics and Statistics. 